\title{
Article \\ A Combined Protective Dose of Angelica archangelica and Ginkgo biloba Restores Normal Functional Hemoglobin Derivative Levels in Rabbits after Oxidative Stress Induced by Gallium-68
}

\author{
Bassem M. Raafat ${ }^{1, *}$, Walaa F. Alsanie ${ }^{2,3}$, Abdulellah Al Thobaity ${ }^{4}$, Abdulhakeem S. Alamri ${ }^{2,3}$ (D), \\ Basem H. Elesawy ${ }^{2}$ and Haytham Dahlawi ${ }^{2}$
}

\section{check for} updates

Citation: Raafat, B.M.; Alsanie, W.F.; Thobaity, A.A.; Alamri, A.S.; Elesawy, B.H.; Dahlawi, H. A Combined Protective Dose of Angelica archangelica and Ginkgo biloba Restores Normal Functional Hemoglobin Derivative Levels in Rabbits after Oxidative Stress Induced by Gallium-68. Appl. Sci. 2021, 11, 4804. https://doi.org/10.3390/app11114804

Academic Editor: Domenico Osella

Received: 9 April 2021

Accepted: 18 May 2021

Published: 24 May 2021

Publisher's Note: MDPI stays neutral with regard to jurisdictional claims in published maps and institutional affiliations.

Copyright: (c) 2021 by the authors. Licensee MDPI, Basel, Switzerland. This article is an open access article distributed under the terms and conditions of the Creative Commons Attribution (CC BY) license (https:/ / creativecommons.org/licenses/by/ $4.0 /)$.
1 Department of Radiological Sciences, College of Applied Medical Sciences, Taif University, P.O. Box 11099, Taif 21944, Saudi Arabia

2 Department of Clinical Laboratory Sciences, College of Applied Medical Sciences, Taif University, P.O. Box 11099, Taif 21944, Saudi Arabia; walaa.alsanie.tu@gmail.com (W.F.A.); a.alamri@tu.edu.sa (A.S.A.); basemelesawy2@gmail.com (B.H.E.); haythamdahlawi@gmail.com (H.D.)

3 Centre of Biomedical Sciences Research (CBSR), Taif University, P.O. Box 11099, Taif 21944, Saudi Arabia

4 Nursing Department, College of Applied Medical Sciences, Taif University, P.O. Box 11099, Taif 21944, Saudi Arabia; Abdulellah.althobaity@hotmail.com

* Correspondence: bassemraafat@tu.edu.sa; Tel.: +966-568883760

\begin{abstract}
Oxidative stress is a physiological imbalance between the production of reactive oxygen species (ROS) and the body's ability to detoxify these products. Oxidative stress induced by ionizing radiation is one of the late biological effects of radiation. The aim of this study was to assess the protective role of Angelica archangelica and Ginkgo biloba extracts, which are commonly used as antioxidants in counteracting effects related to functional and non-functional hemoglobin derivative concentrations, as well as the rate of hemoglobin autoxidation before exposing rabbits to ionizing radiation. The experimental design included four groups of rabbits: a control group that did not receive gallium or antioxidants; Group 1, which received ${ }^{68} \mathrm{Ga}$ isotope as a source of ionizing radiation with no prior treatment; Groups 2 and 3, which received A. archangelica and G. biloba root powder water extracts, respectively, for seven days prior to irradiation; and Group 4, which received a combined dose of both antioxidants, A. archangelica and G. biloba, prior to irradiation, with the same dose, time, and duration as used in Groups 2 and 3. The results demonstrate that both antioxidants had the ability to counteract oxidative stress induced by ionizing radiation, as well as to reduce the hemoglobin autoxidation rate. A synergistic effect was revealed when using a combined dose of both antioxidants at the same concentrations, times, and durations. A lower rate of free radical formation was also recorded, reflected by a reduction in superoxide dismutase (SOD) and glutathione peroxidase activity. The data here presented support the radioprotective role of both investigated antioxidants.
\end{abstract}

Keywords: ${ }^{68} \mathrm{Ga}$; hemoglobin; Angelica archangelica; Ginkgo biloba; oxidative stress

\section{Introduction}

Over the last twenty years, considerable attention has been given to the ${ }^{68} \mathrm{Ga}$ isotope because of its wide commercial availability, resulting from advances in procedures for its purification [1]. Hence, its application in diagnostics has become more dominant for several diseases, replacing some isotopes that are more difficult to prepare [2]. Positron emission tomography (PET) scanning was the first diagnostic tool that used the ${ }^{68} \mathrm{Ga}$ isotope, in the mid-2000s, which is considered to be the starting point for the medical use of this isotope [3]. Significant developments in manufacturing the specific generator used for producing this isotope, i.e., ${ }^{68} \mathrm{Ge} /{ }^{68} \mathrm{Ga}$, have been among the most important factors affecting growth in the medical use of gallium [4]. 
The ${ }^{68} \mathrm{Ga}$ isotope has a half-life of $67.7 \mathrm{~min}$, whereas the parent ${ }^{68} \mathrm{Ge}$ has a half-life of 270.8 days [2]; most ${ }^{68} \mathrm{Ga}$ energy (i.e., $89 \%$ ) decays through positron emission, the maximum beta emission from gallium is $1.92 \mathrm{MeV}$, and the remaining energy is emitted by orbital electron capture. Gamma rays emitted from the ${ }^{68} \mathrm{Ga}$ isotope have higher energy compared with other isotopic emissions and it is therefore associated with a greater occupational health hazard [3].

Oxidative stress is the inability of cells and tissues to detoxify reactive oxygen species (ROS) produced as a result of exposure to ionizing agents [5]; oxidative stress is based on impaired intracellular redox homeostasis due to several types of inducers; for example, ionizing radiation is biologically described as oxidative stress [6]. Elevated oxidative stress leads to the massive production of free radicals, which can result in biological damage and numerous diseases [7]. The oxidative stress level is determined by the body's ability to detoxify the produced ROS. Fatigue, memory loss, muscle and joint pain, decreased vision, headaches, and nose sensitivity are ranked as moderate oxidative stress symptoms [8]. Cancer, respiratory disease, Parkinson's disease, heart disease, arthritis, stroke, immune deficiency, emphysema, and many ischemic or inflammatory conditions are symptoms of higher levels of free radical production [9].

The binding of oxygen to a hemoglobin molecule is highly dependent on the energy state of the iron atom inside the hemoglobin molecule. Oxyhemoglobin $\left(\mathrm{Hb}-\mathrm{O}_{2}\right)$ is the functional (i.e., oxygen-loaded) form of hemoglobin $(\mathrm{Hb})$. When hemoglobin is exposed to oxidizing agents, the heme iron may be converted from a ferrous (+2) to a ferric state $(+3)$, generating methemoglobin $(\mathrm{Met}-\mathrm{Hb})$, which ineffective for the binding and the transport of oxygen $[10,11]$. Other non-functional forms of $\mathrm{Hb}$ are carboxyhemoglobin or carbonylhemoglobin $(\mathrm{Hb}-\mathrm{CO})$ and sulfhemoglobin $(\mathrm{S}-\mathrm{Hb})$, generated respectively by the irreversible coordination of $\mathrm{CO}$ to the heme iron or by the addition of a sulfur atom in the pyrrole ring [12].

The body's intracellular antioxidant defense system is essential for maintaining normal levels of oxyhemoglobin, and the first-line defense antioxidants superoxide dismutase (SOD) and glutathione peroxidase (GPX) are important components of the system responsible for carrying out this essential role [13].

Angelica archangelica, or Norwegian angelica, is a member of the Umbelliferae family, with a long folk history of medical uses [14]. Leaves and roots have commonly been used as traditional treatments for digestive disorders and to enhance blood circulation [15]. The herb root can be crushed and stored for years, thereby allowing its benefits to be saved and then retrieved through water extraction, which is known to produce an extract containing an effective dose of antioxidants. Specifically, root water extracts have been recommended for treating loss of appetite and dyspeptic complaints [16]. The German Commission E Monographs: Therapeutic Guide to Herbal Medicines approved A. archangelica for cold and fever treatment, and also stated that there were no side effects or health hazards from therapeutic use within the recommended dosage [17].

Ginkgo, which is native to China, Japan, and Korea [18], is one of the oldest living trees, dating back more than 200 million years. A Ginkgo biloba tree can live for thousands of years. Ancient traditional medicine books mention Ginkgo biloba as a treatment for memory weakness, anxiety, and vision problems. Reports have stated that in $2600 \mathrm{BCE}$, this herb was used for treating asthma and bronchitis [19]. Studies have verified the effectiveness of Ginkgo biloba for treating premenstrual syndrome (PMS), schizophrenia, Alzheimer's disease, stroke, high blood pressure, multiple sclerosis, tinnitus, movement disorders, dizziness, and sexual problems.

The aim of this study was to investigate the ability of two natural antioxidants, i.e., Angelica archangelica and Ginkgo biloba, to resist oxidative stress caused by exposure to ionizing radiation by considering functional and non-functional hemoglobin derivative levels, as well as the rate by which hemoglobin is returned back to functional reduced forms. 


\section{Materials and Methods}

This study was conducted on 55 male rabbits (Oryctolagus cuniculus), weighing $1.5 \mathrm{~kg}$ ( $\pm 0.1 \mathrm{~kg})$ and aged 2-3 months. The rabbits were fed a standard pelleted rabbit ration ad libitum with free drinking access. The rabbits were subdivided into five groups: a control group (9 rabbits) that did not receive irradiation or antioxidants; Group 1 (G1, 11 rabbits), which received Gallium-68 isotope irradiation; Group 2 (G2, 13 rabbits), which received Angelica archangelica root powder water extraction for 7 days before irradiation; Group 3 (G3, 10 rabbits), which received Ginkgo biloba for 7 days before irradiation; and Group 4 (G4, 12 rabbits), which received a combined dose of both antioxidants for 7 days with the same concentration, time, and duration as in Groups 2 and 3. The experimental design was approved by the ethical committee of Taif University.

An injectable solution of the ${ }^{68} \mathrm{Ga}$ isotope was used, Gallium $\mathrm{Ga}$-68 dotatoc (Rx), in a 30-mL multidose vial containing $18.5-148 \mathrm{MBq} / \mathrm{mL}(0.5-4.0 \mathrm{mCi} / \mathrm{mL})$. The dose was calculated as $2 \mathrm{MBq} / \mathrm{kg}$, identical to the isotopes used commercially in human diagnostic protocols. An intravenous application was used. Before the injections, the rabbits were hydrated with saline injections to ensure adequate isotope absorption. A suitable syringe was used to collect blood samples via the left ear vein, and the samples were then stored in heparinized tubes at $-70^{\circ} \mathrm{C}$ until the analysis procedure was conducted.

Angelica archangelica herb roots were commercially collected from a traditional herb dealer in Egypt. Ginkgo biloba was delivered from public pharmacies as tablets in Saudi Arabia. A. archangelica and G. biloba protective doses were calculated based on a $0.11 \mathrm{~g} / \mathrm{kg}$ body weight [17].

The derivative concentrations of hemoglobin were measured using a modified BeerLambert law. Spectrophotometrically, the four types of hemoglobin (oxyhemoglobin $\left(\mathrm{HbO}_{2}\right)$, carboxyhemoglobin $(\mathrm{HbCO})$, sulfhemoglobin $(\mathrm{SHb})$, and methemoglobin (Met.HB) had characteristic pigment peaks. Four linear equations were obtained at wavelengths of $500,569,577$, and $620 \mathrm{~nm}$, respectively. A matrix instant solution of the four equations was carried out to calculate each derivative concentration separately.

The millimolar extinction coefficients are presented in the following equations with the four unknown concentrations of hemoglobin pigments $\left(\mathrm{C}_{\mathrm{Hb}-\mathrm{O} 2}, \mathrm{C}_{\mathrm{Hb}-\mathrm{CO}}, \mathrm{C}_{\mathrm{Met}-\mathrm{Hb}}\right.$, and $\mathrm{C}_{\mathrm{Hb}-\mathrm{S}}$ [19]:

$$
\begin{aligned}
& A^{500}=5.05 \mathrm{C}_{\mathrm{HbO}_{2}}+5.35 \mathrm{C}_{\mathrm{HbCO}}+9.04 \mathrm{C}_{\mathrm{Met} . \mathrm{Hb}}+7.2 \mathrm{C}_{\mathrm{SHb}} \\
& A^{569}=11.27 \mathrm{C}_{\mathrm{HbO}_{2}}+14.27 \mathrm{C}_{\mathrm{HbCO}}+4.1 \mathrm{C}_{\mathrm{Met.Hb}}+8.1 \mathrm{C}_{\mathrm{SHb}} \\
& A^{577}=15.37 \mathrm{C}_{\mathrm{HbO}_{2}}+10.0 \mathrm{C}_{\mathrm{HbCO}}+4.1 \mathrm{C}_{\mathrm{Met} . \mathrm{Hb}}+8.1 \mathrm{C}_{\mathrm{SHb}} \\
& A^{620}=0.24 \mathrm{C}_{\mathrm{HbO}_{2}}+0.33 \mathrm{C}_{\mathrm{HbCO}}+3.35 \mathrm{C}_{\mathrm{Met.Hb}}+20.8 \mathrm{C}_{\mathrm{SHb}}
\end{aligned}
$$

The above linear system of equations can be represented in matrix form as:

$$
\left[\begin{array}{cccc}
5.05 & 5.35 & 9.04 & 7.2 \\
11.27 & 14.27 & 4.10 & 8.1 \\
15.37 & 10.0 & 4.10 & 8.1 \\
0.24 & 0.33 & 3.35 & 20.8
\end{array}\right] \cdot\left[\begin{array}{c}
\mathrm{C}_{\mathrm{HbO}_{2}} \\
\mathrm{C}_{\mathrm{HbCO}} \\
\mathrm{C}_{\mathrm{Met.Hb}} \\
\mathrm{C}_{\mathrm{SHb}}
\end{array}\right]=\left[\begin{array}{c}
\mathrm{A}^{500} \\
A^{569} \\
A^{577} \\
A_{620}
\end{array}\right]
$$

Mathematically, this is a linear equation system and can be solved by the process of manipulation. The Gaussian elimination method was used to calculate the different derivative concentrations. Matrix calculations resulted in the following equations, which could be used to calculate each concentration separately, where $A_{500}, A_{569}, A_{577}$, and $A_{620}$ are the spectrophotometric absorbances of the hemoglobin solution at the wavelengths 500 , 569,577 , and $620 \mathrm{~nm}$, respectively.

The monitoring of the hemoglobin autoxidation rate was carried out spectrophotometrically, as described by [20], in air-saturated $0.1 \mathrm{M}$ phosphate buffer, $\mathrm{pH} 7.05$, with $2 \mathrm{mg} / \mathrm{mL}$ $\mathrm{HbO}_{2}$. Hemoglobin molecules were lysed in cold distilled water and hemolysis was carried out at $6000 \mathrm{rpm}$ centrifugation. The $\mathrm{pH}$ of the hemoglobin solution was checked before 
and after each experiment, and spectra of hemoglobin were recorded using a UV-Visible spectrophotometer (Shimadzu-UV-1800). An absorbance value at a wavelength of $630 \mathrm{~nm}$ is characteristic for methemoglobin derivative. A graph was constructed to demonstrate the rate by which this nonfunctional derivative was formed in a time range of eight hours [20].

The superoxide dismutase (SOD) and glutathione peroxidase (GPx) activities were determined using Randox kits specific to the measured activity (cat. no. SD 125 and RS 504, respectively, Salima Corp. Est., Riyadh, Saudi Arabia).

The statistical analysis was carried out using SPSS 10.00 for Windows (SPSS Inc., Chicago, IL, USA). Student's $t$-test was chosen according to the experimental design. The data are represented as mean and standard deviation. Results were considered statistically significant when $p<0.05$.

\section{Results}

The data in Table 1 and Figure 1 demonstrate the different hemoglobin derivative concentrations of rabbits injected with ${ }^{68} \mathrm{Ga}$ with no application of antioxidant protective treatment before irradiation. It can be observed that there was no significant change in total hemoglobin concentration after isotopic injection as compared with the control group. Different hemoglobin derivatives showed obvious effects, with all non-functional derivatives, $\mathrm{S}-\mathrm{Hb}$, Met- $\mathrm{Hb}$, and $\mathrm{Hb}-\mathrm{CO}$, recording a significant increase as compared with the control group. Oxyhemoglobin, a functional derivative, showed a highly significant decrease $(97 \%$ to $81 \%)$. The oxidized form of hemoglobin was revealed to be the most affected derivative (increasing from $1 \%$ to $8 \%$ ).

Table 1. Hemoglobin derivative concentrations of rabbits injected with $2 \mathrm{MBq} / \mathrm{kg}$ Gallium-68 (G1) as compared with the control group (mean $\pm \mathrm{SE}$ ).

\begin{tabular}{ccccc}
\hline & \multicolumn{2}{c}{ Control } & \multicolumn{2}{c}{${ }^{\mathbf{6 8}}$ Ga Injected Rabbits (G1) } \\
\hline $\mathrm{g} / \mathrm{dL}$ & $\mathbf{\%}$ & $\mathrm{g} / \mathrm{dL}$ & $\mathbf{\%}$ \\
\hline $\mathrm{S}-\mathrm{Hb}$ & $0.03 \pm 0.001$ & 0.17 & $0.17 \pm 0.02^{*}$ & 0.98 \\
$\mathrm{Met}-\mathrm{Hb}$ & $0.17 \pm 0.01$ & 0.9 & $1.37 \pm 0.03^{* *}$ & 8.1 \\
$\mathrm{Hb}-\mathrm{CO}$ & $0.27 \pm 0.02$ & 1.5 & $1.67 \pm 0.19^{* *}$ & 9.9 \\
$\mathrm{Hb}-\mathrm{O}_{2}$ & $16.56 \pm 0.96$ & 97.2 & $13.77 \pm 1.16^{* *}$ & 80.8 \\
Total Hb & $17.0 \pm 0.70$ & 100 & $16.27 \pm 1.02^{*}$ & 100 \\
\hline * & &
\end{tabular}
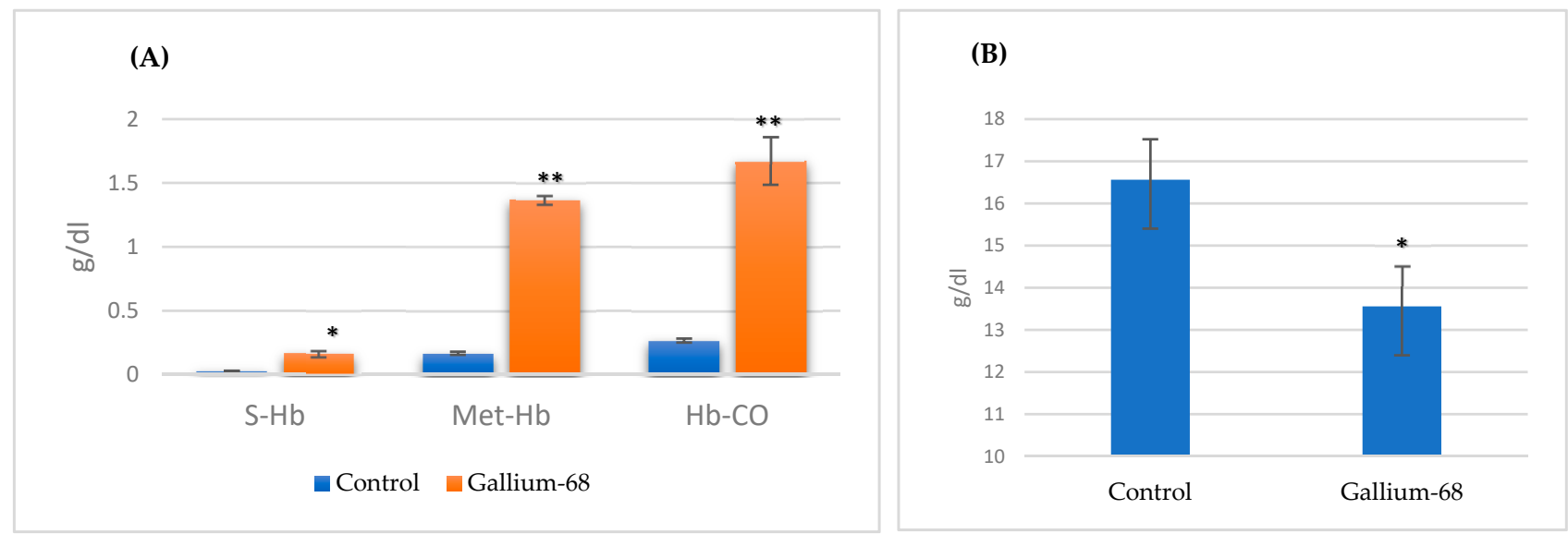

Figure 1. (A) Sulfhemoglobin, methemoglobin, and carboxyhemoglobin derivative concentrations after ${ }^{68} \mathrm{Ga}$ injection as compared to control. (B) Oxyhemoglobin derivative concentration after ${ }^{68} \mathrm{Ga}$ injection as compared to control. ${ }^{*}$ Significant $p<0.05$ and ${ }^{* *}$ highly significant $p<0.01$.

The data in Table 2 and Figure 2 show the hemoglobin derivative concentrations for rabbits injected with Gallium-68 after seven days of Angelica archangelica and Ginkgo 
biloba application as a protective antioxidant treatment before irradiation. The rabbits that received antioxidants, i.e., A. archangelica or G. biloba, prior to Gallium-68 injection showed a significant increase in functional derivatives. The rabbits that received a combined dose of both antioxidants in the same experimental conditions, dose, time, and duration showed the greatest enhancement of oxyhemoglobin $(15.35 \pm 1.24 \mathrm{~g} / \mathrm{dL})$. In addition, the non-functional hemoglobin derivative showed a significant decrease from $8 \%$ to $2 \%$ with gallium injection.

Table 2. Hemoglobin derivative concentrations in rabbits injected with $2 \mathrm{MBq} / \mathrm{kg}$ Gallium-68 after seven days of protective oral antioxidant treatment as indicated (G2-G4) (Mean $\pm \mathrm{SE}$ ).

\begin{tabular}{ccccccc}
\hline & \multicolumn{2}{c}{ Angelica archangelica (G2) } & \multicolumn{2}{c}{ Ginkgo biloba (G3) } & \multicolumn{2}{c}{ Combined Dose (G4) } \\
\hline & g/dL & \% & g/dL & \% & g/dL & \% \\
\hline $\mathrm{S}-\mathrm{Hb}$ & $0.08 \pm 0.006^{*}$ & 0.5 & $0.09 \pm 0.003$ & 0.5 & $0.06 \pm 0.002 *$ & 0.3 \\
$\mathrm{Met}-\mathrm{Hb}$ & $0.64 \pm 0.04 *$ & 3.9 & $0.59 \pm 0.04 *$ & 3.8 & $0.39 \pm 0.02 *$ & 2.5 \\
$\mathrm{Hb}-\mathrm{CO}$ & $0.62 \pm 0.03$ & 3.9 & $0.57 \pm 0.03$ & 3.6 & $0.36 \pm 0.02$ & 2.3 \\
$\mathrm{Hb}-\mathrm{O}_{2}$ & $14.63 \pm 1.14 *$ & 91.5 & $14.23 \pm 0.94 * *$ & 91.9 & $15.35 \pm 1.24 *$ & 95 \\
Total Hb & $15.97 \pm 1.23 *$ & & $15.48 \pm 1.21 *$ & & $16.15 \pm 1.02 *$ & \\
\hline
\end{tabular}

* Significant $p<0.05$ and ${ }^{* *}$ highly significant $p<0.01$.
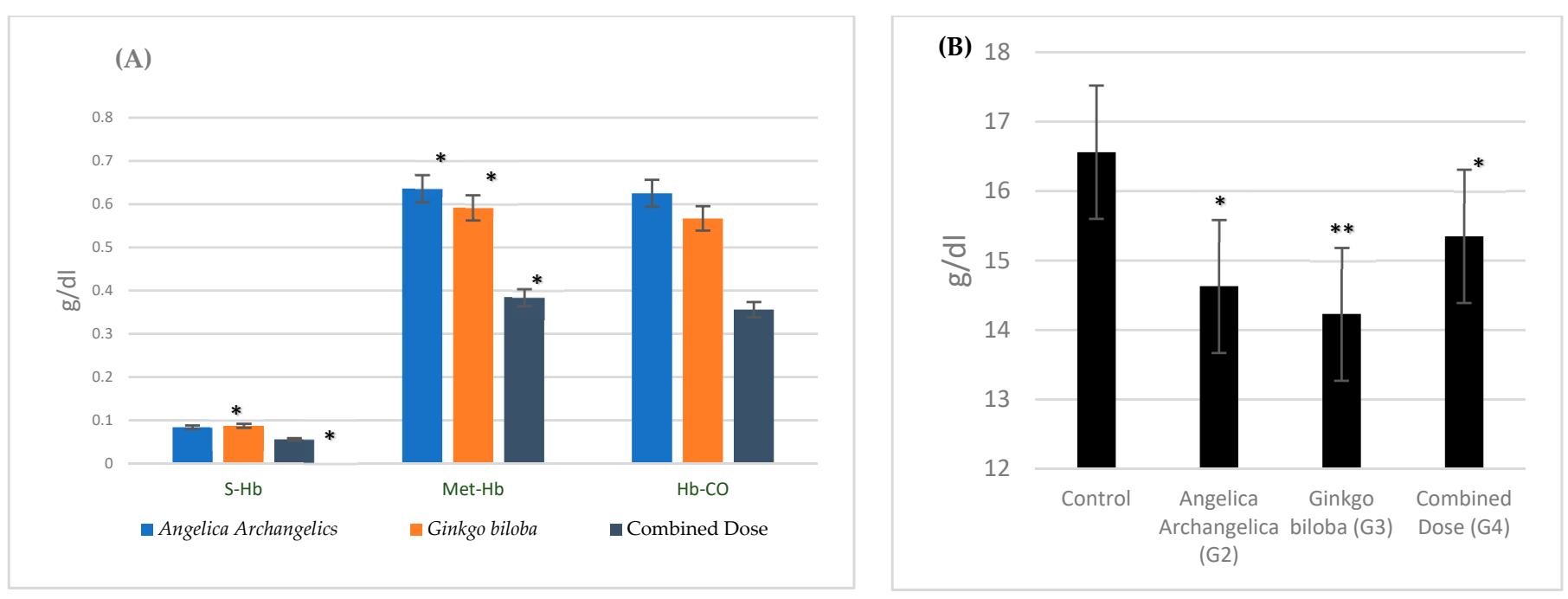

Figure 2. (A) Sulfhemoglobin, methemoglobin, and carboxyhemoglobin derivative concentrations in rabbits injected with ${ }^{68} \mathrm{Ga}$ after antioxidant treatment for seven days. (B) Oxyhemoglobin derivative concentrations of rabbits injected with ${ }^{68} \mathrm{Ga}$ after antioxidant treatment for seven days. ${ }^{*}$ Significant $p<0.05$ and ${ }^{* *}$ highly significant $p<0.01$.

The superoxide dismutase (SOD) and glutathione peroxidase (GPX) activities in the blood of rabbits injected with Gallium-68 with and without prior protection with Angelica archangelica and Ginkgo biloba are shown in Table 3. A highly significant increase in both activities was recorded after Gallium-68 injection $(467.37 \pm 21.04$ and $9325.45 \pm 411.45 \mathrm{U} / \mathrm{mL}$ ), respectively. An obvious enhancement in oxidative protection was found when the supplemented antioxidants were applied daily before injection, as reflected by lower enzyme activities-288.12 \pm 16.55 and $277.15 \pm 16.15 \mathrm{U} / \mathrm{mL}$ for SOD in G2 and G3, and $6346.45 \pm 522.45$ and $7123.76 \pm 416.24 \mathrm{U} / \mathrm{mL}$ for GPX in G2 and G3. The combined dose of both supplements revealed the best results in terms of highly significant lowered antioxidant activity $-156.67 \pm 11.14$ and $5229.12 \pm 356.12 \mathrm{U} / \mathrm{mL}$, respectively. 
Table 3. Superoxide dismutase (SOD) and glutathione peroxidase (GPX) activity of the rabbits that received the Gallium-68 injection with and without protective antioxidants Angelica archangelica and Ginkgo biloba, as well as with a combined dose as compared with the control group (Mean $\pm \mathrm{SE}$ ).

\begin{tabular}{ccc}
\hline & SOD $(\mathrm{U} / \mathrm{mL})$ & GPX $(\mathrm{U} / \mathrm{mL})$ \\
\hline Control & $144.24 \pm 12.15$ & $4134.14 \pm 354.34$ \\
G1 & $467.37 \pm 21.04^{* *}$ & $9325.45 \pm 411.45^{* *}$ \\
G2 & $288.12 \pm 16.55^{*}$ & $6346.45 \pm 522.45^{*}$ \\
G3 & $277.12 \pm 16.15^{*}$ & $7123.76 \pm 416.24^{*}$ \\
G4 & $156.67 \pm 11.14^{* *}$ & $5229.12 \pm 356.12^{* *}$ \\
\hline
\end{tabular}

* Significant $p<0.05$ and ${ }^{* *}$ highly significant $p<0.01$.

The rate at which hemoglobin is converted to the oxidized form, i.e., the hemoglobin autoxidation rate, was measured, and the results are shown in Figure 3. A highly oxidized pattern was recorded in the hemoglobin of rabbits that received Gallium-68 with no prior proactive treatment with antioxidants. Groups 2 and 3 revealed lower rates of autoxidation than the groups that received no treatment before exposure to radiation, but a lowest rate was observed in rabbits that received a combined dose of antioxidants (Group 4 (G4)).
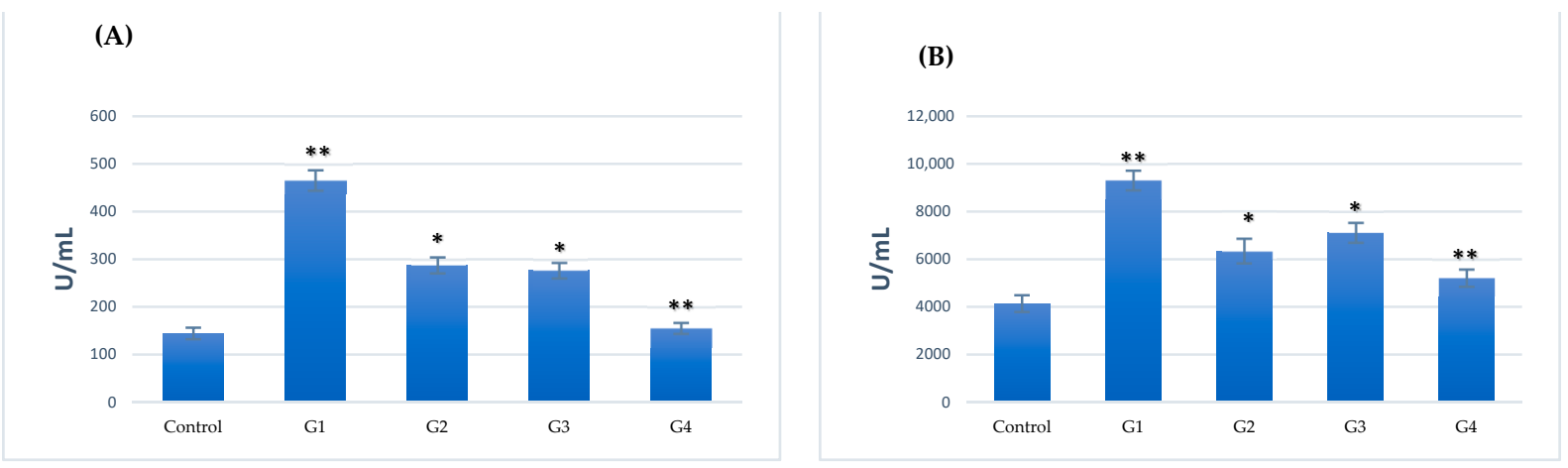

Figure 3. (A) Superoxide dismutase (SOD) activity after Gallium-68 injection with and without protective treatment with Angelica archangelica and Ginkgo biloba; (B) glutathione peroxidase (GPX) activity after Gallium-68 injection with and without protective treatment with Angelica archangelica and Ginkgo biloba. ${ }^{*}$ Significant $p<0.05$ and ${ }^{* *}$ highly significant $p<0.01$.

\section{Discussion}

The importance of studying the hazardous effects of the ${ }^{68} \mathrm{Ga}$ isotope is concomitant with its recently expanded medical usage, resulting from its ready availability, easy generation, specific uptake by tumor cells, and amenability to one-step chelation, which are the main factors that have made it more pharmaceutically applicable, even in small medical institutions, compared to some other isotopes. Over the last ten years, the use of the ${ }^{68} \mathrm{Ga}$ isotope in positron emission tomography (PET) scanning has rapidly increased to the extent that it has led to problems in supply [1]. On the one hand, the production and storage of the ${ }^{68} \mathrm{Ga}$ isotope is simple and easy because of its long half-life parent nuclide (270.93 days) [20]; on the other hand, during this propagated usage, attention should be drawn to the undesired effects of exposure to ionizing radiation.

Oxidative stress is a well-established effect of ionizing radiation that results either from the direct interaction of radiation with target macromolecules or from the radiolysis of water products, which affects target molecules and can be propagated to neighboring cells and tissues. Oxidative stress can be biologically produced through exposure to several inducers and not only ionizing radiation. A recent study revealed that oxidative stress resulted from exposure to ionizing radiation emitted from the ${ }^{68} \mathrm{Ga}$ isotope used in nuclear medicine and was a cause of radiation-induced heart disease (RIHD) [21]. Generally, oxidative stress mainly depends on the body's health, especially the body's ability to resist it and detoxify the produced ROS. 
Hemoglobin, with its direct relation and interaction with oxygen molecules during gas transportation within the body, is considered to be one of the molecules that is most sensitive to oxidative stress. Blood hemoglobin, with its quaternary structure, has two pairs of nonidentical proteins, alpha with 141 amino acids and beta with 146 amino acids, which are hemoglobin transporters that act together to carry oxygen and carbon dioxide to and from cells [21]. The oxygen affinity of hemoglobin is the ability of its molecules to capture oxygen molecules which are higher in arterial circulation. The oxygen affinity property of hemoglobin mainly depends on the status of the iron atom inside the porphyrin ring. This very sensitive condition is the main principle that reflects alterations in hemoglobin function when subjected to any ionization [22]. Oxidative stress due to the excessive formation of reactive oxygen species (ROS) is one of the most common processes when blood is exposed to radioactive isotopes $[5,23]$. In elevated oxidative stress situations, the essential redox system may need external supplementation to restore the direct and indirect imbalance of ROS. The aim of this study was to investigate the extent to which the use of oral antioxidants prior to ionizing radiation exposure could counteract oxidative stress.

Angelica archangelica root water extract has wide medical uses as an antioxidant because of its main active ingredients, which include $\alpha$-pinene $(15.7-20.8 \%), \delta$-3-carene (15.4-16.9\%), limonene (8.0-9.2\%), $\beta$-phellandrene (13.5-15.4\%), $\alpha$-phellandrene (8.0-9.1\%), and $p$-cymene (6.8-10.6\%) [24]. The antioxidant activity of $A$. archangelica essentially dependents on the mode of extraction, which controls variable radical scavenging and the level of peroxidation activities. Regarding different higher modes of chemical extraction, A. archangelica contains 1,1-diphenyl-2-picrylhydrazil (DPPH), 2,2-azino-bis (3ethylbenzothiazoline-6-sulfonic acid (ABTS), and $\beta$-carotene, and these active ingredients are believed to increase the antioxidant activity of extracts.

G. biloba contains three major chemical active ingredients: ginkgolides, bilobalides, and flavonoids. Such compounds are found in extracts such as flavanol, flavone glycosides, ascorbic acid, catechin, iron-based superoxide, protocatechuic acid, sterols, and vanillic acid [23]. G. biloba has a long history of use in traditional medicine for the protection of neurons from damage due to oxidation, the prevention of tissue degeneration in dementia patients, improving blood flow and circulation throughout the body, and restoring prostacyclin and thromboxane A2, which improves vasoregulation.

Previous chemical analysis of the antioxidants in A. archangelica and G. biloba has demonstrated that both of these plants have antioxidant activities. A study was carried out to assess their ability to inhibit oxidative stress as a protective treatment against injuries of the eye lens and confirmed that the use of both herbs before radiation exposure significantly controlled ROS [23]. In healthy blood, oxyhemoglobin should be the most abundant derivative and levels must be above $97 \%$ to ensure normal gas transportation. This derivative has high sensitivity to free radicals, as a tiny amount of ROS can alter its iron atom electrical properties and produce another form of hemoglobin, Met- $\mathrm{Hb}$. In this study, different hemoglobin derivative concentrations were calculated and are shown in Table 1 and Figure 1. Rabbits that were exposed to radiation by means of Gallium-68 injections with no prior protective antioxidant treatment revealed a highly significant decrease in oxyhemoglobin concentrations, with a highly significant increase in the oxidized form of hemoglobin, methemoglobin. Exposure to ionizing radiation only and with no prior antioxidant treatment resulted in the excessive production of ROS, which played a role in an array of oxidation events that resulted in higher levels of oxidized hemoglobin derivative, i.e., methemoglobin, with a significant reduction in the levels of oxyhemoglobin (G1). This effect seemed to be controlled by the application of both antioxidants, A. angelica and G. biloba, i.e., Groups 2 and 3, for seven days before exposure to radiation.

Another method to determine whether both these antioxidants can play a role as protective treatments against cell oxidative stress is to study the activity level of natural body antioxidants. Hemoglobin molecules are continuously involved in oxidation reduction. The human bodyguards, SOD and GPX, play an essential role in maintaining normal functional derivatives such that hemoglobin is able to carry out its normal functions. The 
activity of these antioxidants is normally increased when blood is exposed to an oxidizing agent, such as ionized radiation, in order to restore the reduced form of molecules [24]. Therefore, an assessment of the activities of these antioxidants could show the existence of free radicals. The data in Table 3 and Figure 3 show significant increases in both antioxidants after Gallium-68 injection, and they clearly show that additional protective antioxidant supplementation before injection leads to enhanced resistance. Treatment with A. angelica and G. biloba, i.e., G2 and G3, increased hemoglobin's oxidative stress resistance, and combined treatment with both antioxidants with the same doses, time, and duration resulted in better outcomes.

Autoxidation of hemoglobin is the rate at which hemoglobin is converted to a nonfunctional derivative due to its direct exposure to reactive species. Hemoglobin resistance to this process is a factor that can describe healthy hemoglobin [25]. Recently, hemoglobin engineering studies have focused on how to improve hemoglobin health by reducing its autoxidation rate [26]. Spectrophotometrically, the methemoglobin derivative has a characteristically higher energy state of its iron atoms, with a peak at $630 \mathrm{~nm}$, which is completely absent in a normal healthy state [27]. In normal incubation circumstances, a dramatic methemoglobin formation rate means that a blood sample contains more oxidized activity [28]. Our findings, presented in Table 4 and Figure 4, show a higher autoxidation rate in rabbits injected with Gallium-68 with no prior treatment, whereas rabbits that received protective antioxidant doses exhibited lower autoxidation rates. It should be highlighted that in Group 4, the rabbits were treated with a combined dose before injection, and the autoxidation rate of this group was approximately normal.

Table 4. Hemoglobin autoxidation rate of rabbits exposed to radiation by Gallium-68 injection, injected with ${ }^{68} \mathrm{Ga}$ protective treatment with Angelica archangelica (G2) and Ginkgo biloba (G3), as well as those with the combined dose as compared with the control (G4).

\begin{tabular}{ccccccccc}
\hline & \multicolumn{8}{c}{ Absorbance at 630 nm } \\
\hline Time (h) & $\mathbf{1}$ & $\mathbf{2}$ & $\mathbf{3}$ & $\mathbf{4}$ & $\mathbf{5}$ & $\mathbf{6}$ & $\mathbf{7}$ & $\mathbf{8}$ \\
\hline Control & 0.534 & 0.897 & 1.345 & 1.789 & 1.998 & 2.456 & 2.985 & 3.345 \\
G1 & 0.678 & 2.567 & 4.678 & 5.678 & 6.875 & 7.456 & 8.567 & 9.456 \\
G2 & 0.678 & 1.087 & 1.945 & 2.789 & 3.998 & 3.456 & 3.985 & 4.345 \\
G3 & 0.576 & 1.234 & 1.876 & 2.998 & 4.998 & 3.956 & 4.185 & 5.345 \\
G4 & 0.511 & 0.697 & 1.605 & 1.78 & 2.345 & 2.156 & 3.985 & 3.945 \\
\hline
\end{tabular}

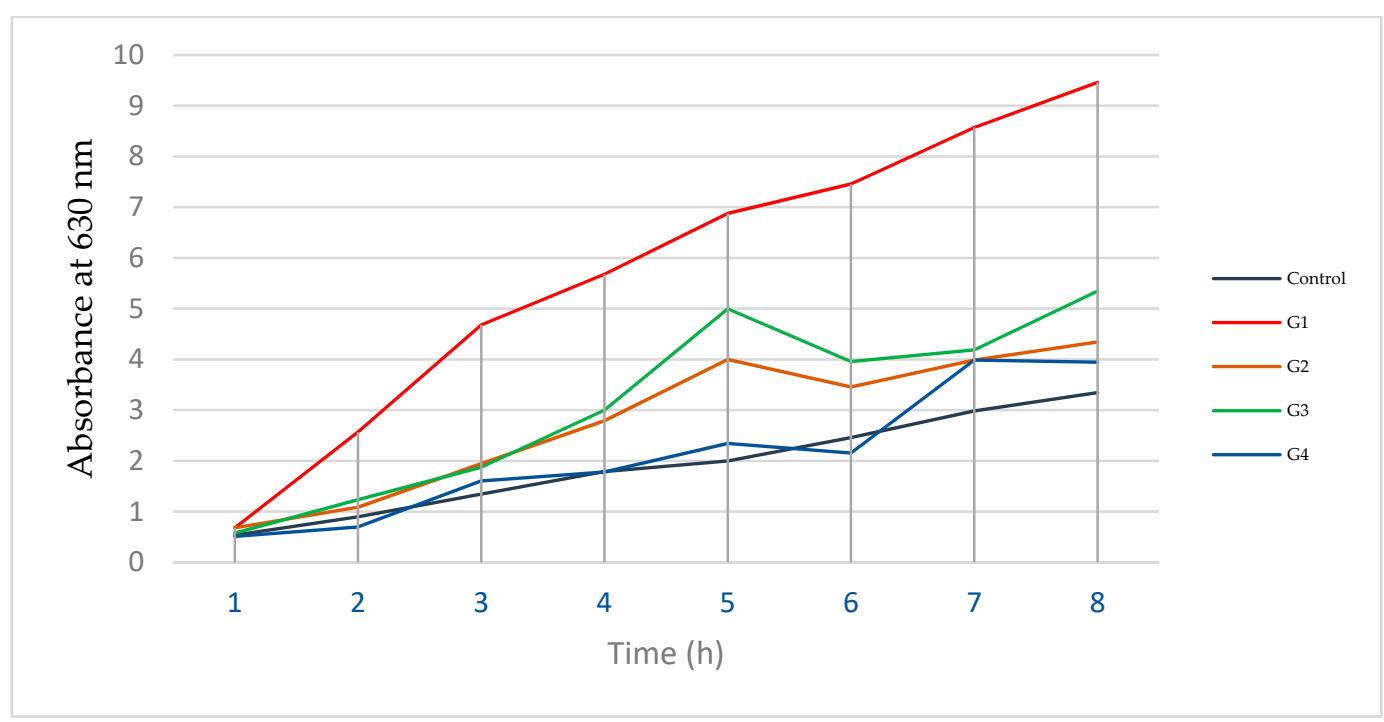

Figure 4. Hemoglobin autoxidation rate in rabbits injected with Gallium-68 with and without the application of protective antioxidants, single and combined doses, as compared with the control. 


\section{Conclusions}

Functional hemoglobin derivatives and antioxidant activity were restored by the application of oral antioxidants, A. archangelica and G. biloba, based on body weight, through the inhibition of the rapid formation of free radicals induced by ionizing radiation from Gallium-68 injections. Overall, oxidative stress was reduced by protective antioxidant application, and better results were obtained with a combined dose of both antioxidants. This study may support the usage of A. archangelica and G. biloba as a preparatory step before exposure to ionizing radiation.

Author Contributions: Conceptualization, B.M.R. and W.F.A.; methodology, B.M.R. and A.A.T.; validation, W.F.A., H.D. and B.H.E.; formal analysis, B.M.R.; investigation, B.H.E.; resources, W.F.A.; data curation, A.A.T.; writing—original draft preparation, W.F.A.; writing—review and editing, H.D. and A.S.A.; visualization, A.A.T. and H.D.; supervision, B.M.R. and A.S.A. All authors have read and agreed to the published version of the manuscript.

Funding: This research received no external funding, only supported by Taif University-Researchers Supporting Project, TURSP.

Institutional Review Board Statement: The study was conducted according to the guidelines of the Declaration of Helsinki and approved by Taif University Ethics Committee. Approval; No. 41-00195.

Data Availability Statement: Data included in this study will be available upon request through the corresponding author.

Acknowledgments: This work was supported by Taif University. Researchers Supporting Project Number [TURSP-2020/53].

Conflicts of Interest: The authors declare no conflict of interest.

\section{References}

1. Kumar, K. The Current Status of the Production and Supply of Gallium-68. Cancer Biother. Radiopharm. 2020, 35, 163-166. [CrossRef] [PubMed]

2. Banerjee, S.R.; Pomper, M.G. Clinical applications of Gallium-68. Appl. Radiat. Isot. 2013, 76, 2-13. [CrossRef]

3. Crown, A.; Rocha, F.G.; Raghu, P.; Lin, B.; Funk, G.; Alseidi, A.; Hubka, M.; Rosales, J.; Lee, M.; Kennecke, H. Impact of initial imaging with gallium-68 dotatate PET/CT on diagnosis and management of patients with neuroendocrine tumors. J. Surg. Oncol. 2020, 121, 480-485. [CrossRef]

4. Al-Nahhas, A.; Win, Z.; Szyszko, T.; Singh, A.; Nanni, C.; Fanti, S.; Rubello, D. Gallium-68 PET: A new frontier in receptor cancer imaging. Anticancer Res. 2007, 27, 4087-7094. [PubMed]

5. Rifkind, J.M.; Mohanty, J.G.; Nagababu, E.; Salgado, M.T.; Cao, Z. Potential Modulation of Vascular Function by Nitric Oxide and Reactive Oxygen Species Released From Erythrocytes. Front. Physiol. 2018, 9, 690. [CrossRef]

6. Deterding, L.J; Ramirez, D.C.; Dubin, J.R.; Mason, R.P.; Tomer, K.B. Identification of free radicals on hemoglobin from its self-peroxidation using mass spectrometry and immuno-spin trapping: Observation of a histidinyl radical. J. Biol. Chem. 2004, 279, 11600-11607. [CrossRef] [PubMed]

7. Mot, A.C.; Damian, G.; Sarbu, C.; Silaghi-Dumitrescu, R. Redox reactivity in propolis: Direct detection of free radicals in basic medium and interaction with hemoglobin. Redox Rep. 2009, 14, 267-274. [CrossRef]

8. Ajibola, K.A.; Ajibola, K.A.; Adedokun, K.A.; Oduola, T.; Oparinde, D.P.; Ayelagbe, O.G.; Ojokuku, H.O. Assessment of iron status and interplay between lipid peroxidation and antioxidant capacity in common hemoglobin variants in Osun State, southwestern Nigeria. Kaohsiung J. Med. Sci. 2019, 35, 358-364. [CrossRef] [PubMed]

9. Alayash, A.I.; Cashon, R.E. Hemoglobin and free radicals: Implications for the development of a safe blood substitute. Mol. Med. Today 1995, 1, 122-127. [CrossRef]

10. Suman, S.G.; Gretarsdottir, J.M. Chemical and Clinical Aspects of Metal-Containing Antidotes for Poisoning by Cyanide. Essent. Met. Med. Ther. Use Toxic. Met. Ions Clin. 2019, 19, 359-391.

11. Umbreit, J. Methemoglobin-It's not just blue: A concise review. Am. J. Hematol. 2007, 82, 134-144. [CrossRef]

12. Tang, M.; Zhou, Y.; Zhang, R.; Wang, L.V. Noninvasive photoacoustic microscopy of methemoglobin in vivo. J. Biomed. Opt. 2015, 20, 036007. [CrossRef] [PubMed]

13. Tovar-García, A.; Angarita-Zapata, V.; Cazares, A.; Jasso-Chávez, R.; Belmont-Díaz, J.; Sanchez-Torres, V.; López-Jacome, L.E.; Coria-Jiménez, R.; Maeda, T.; García-Contreras, R. Characterization of gallium resistance induced in a Pseudomonas aeruginosa cystic fibrosis isolate. Arch. Microbiol. 2020, 202, 617-622. [CrossRef] 
14. Koshinski, R.; Velichkova, K.; Sirakov, I.; Stoyanova, S. Effect of Angelica archangelica L. Extract on growth performance, meat quality and biochemical blood parameters of rainbow trout (Oncorhynchus mykiss W.), cultivated in a recirculating system. Bulg. J. Agric. Sci. 2020, 26, 232-237.

15. Fraternale, D.; Teodori, L.; Rudov, A.; Prattichizzo, F.; Olivieri, F.; Guidarelli, A.; Albertini, M.C. The in Vitro Activity of Angelica archangelica L. Essential Oil on Inflammation. J. Med. Food 2018, 21, 1238-1243. [CrossRef]

16. Cyr, B. Methods and Therapeutic Compositions Comprising Plant Extracts for the Treatment of Cancer. U.S. Patent 12/762, 23 December 2010.

17. Raafat, B.M.; Zahrany, S.M.; Al-Zahrani, A.S.; Tawifiek, E.; Al-Omery, A.M. Angelica archangelica roots water extraction as a natural antioxidant tolerating ros production in lead poisoning. Res. J. Pharm. Biol. Chem. Sci. 2012, 3, 795-806.

18. Jackson, P.A.; Forster, J.S.; Bell, J.G.; Dick, J.R.; Younger, I.; Kennedy, D.O. Dha supplementation alone or in combination with other nutrients does not modulate cerebral hemodynamics or cognitive function in healthy older adults. Nutrients $2016,8,86$. [CrossRef]

19. McCord, T.B.; Elias, J.H.; Westphal, J.A. Mars: The spectral albedo $(0.3-2.5 \mu)$ of small bright and dark regions. Icarus 1971, 14, 245-251. [CrossRef]

20. Velikyan, I. 68Ga-based radiopharmaceuticals: Production and application relationship. Molecules 2012, 20, 12913-12943. [CrossRef] [PubMed]

21. Guillochon, D.; Esclade, L.; Thomas, D. Effect of glutaraldehyde on haemoglobin: Oxidation-reduction potentials and stability. Biochem. Pharmacol. 1986, 35, 317-323. [CrossRef]

22. Ping, Z.; Peng, Y.; Lang, H.; Xinyong, C.; Zhiyi, Z.; Xiaocheng, W.; Hong, Z.; Liang, S. Oxidative Stress in Radiation-Induced Cardiotoxicity. Oxidative Med. Cell. Longev. 2020, 2020. [CrossRef] [PubMed]

23. Khedr, M.H.; Shafaa, M.W.; Abdel-Ghaffar, A.; Saleh, A. Radioprotective efficacy of Ginkgo biloba and Angelica archangelica extract against technetium-99m-sestamibi induced oxidative stress and lens injury in rats. Int. J. Radiat. Biol. 2018, 94, 37-44. [CrossRef] [PubMed]

24. Meher, P.K.; Mishra, K.P. A Prospective Study Comparing Hemoglobin Levels and Response in. N. Engl. J. Med. 2017, 357, 122-126.

25. Irshad, M.; Habib-Ur-Rehman Shahid, M.; Aziz, S.; Ghous, T. Antioxidant, antimicrobial and phytotoxic activities of essential oil of angelica glauca. Asian J. Chem. 2011, 23, 1947.

26. Roh, J.; Shin, S. Antifungal and antioxidant activities of the essential oil from Angelica Koreana Nakai. Evid. Based Complement. Altern. Med. 2014, 2014. [CrossRef]

27. He, Y.; Gong, Y.; Lin, J.; Chang, D.W.; Gu, J.; Roth, J.A.; Wu, X. Ionizing radiation-induced $\gamma-\mathrm{H} 2 \mathrm{AX}$ activity in whole blood culture and the risk of lung cancer. Cancer Epidemiol. Biomark. Prev. 2013, 22, 443-451. [CrossRef]

28. Cooper, C.E.; Silkstone, G.G.A.; Simons, M.; Gretton, S.; Rajagopal, B.S.; Allen-Baume, V.; Syrett, N.; Shaik, T.; Popa, G.; Sheng, X.B.; et al. Engineering hemoglobin to enable homogenous PEGylation without modifying protein functionality. Biomater. Sci. 2020, 8, 3896-3906. [CrossRef] [PubMed] 